\title{
Evaluation of Capability of Some Amino Acid-based Poly (Ionic Liquid)s as Biocompatible Agent for $\mathrm{Co} 2$ Absorption
}

Narmin Noorani ( $\square$ nnorani1@yahoo.com )

University of Tabriz https://orcid.org/0000-0002-8156-2018

Abbas Mehrdad

University of Tabriz

\section{Research Article}

Keywords: AAPILs, Thermodynamics, Absorption, CO2

Posted Date: December 14th, 2021

DOI: https://doi.org/10.21203/rs.3.rs-1123236/v1

License: (c) (i) This work is licensed under a Creative Commons Attribution 4.0 International License.

Read Full License 
Evaluation of capability of some amino acid-based poly (ionic liquid)s as biocompatible agent for $\mathrm{CO}_{2}$ absorption

Narmin Noorani*, Abbas Mehrdad

Department of Physical Chemistry, Faculty of Chemistry, University of Tabriz, Tabriz, Iran

\begin{abstract}
In this study, seven amino acid-based poly(ionic liquid)s (AAPILs) such as poly(1-butyl-3vinylimidazolium glycinate), P[VBIm][Gly], poly (1-butyl-3-vinylimidazolium alaninate), $\mathrm{P}[\mathrm{VBIm}][\mathrm{Ala}], \quad$ poly(1-butyl-3-vinylimidazolium valinate), P[VBIm][Val], poly(1-butyl-3vinylimidazolium prolinate) P[VBIm][Pro], poly(1-butyl-3-vinylimidazolium hisdinate), P[VBIm][His], poly(1-butyl-3-vinylimidazolium lysinate), P[VBIm][Lys], and poly(1-butyl-3vinylimidazolium arginate), $\mathrm{P}[\mathrm{VBIm}][\mathrm{Arg}]$ have been synthesized, characterized, and their $\mathrm{CO}_{2}$ absorption capacities were investigated using quartz crystal microbalance (QCM) at temperature range 288.15-308.15 and pressures up to 5 bar. Based on the absorption mechanism, the reaction equilibrium thermodynamic model is applied to correlating the experimental $\mathrm{CO}_{2}$ absorption capacities. The reaction equilibrium constant and Henry's law constant were calculated to evaluate the efficiency of the AAPILs for $\mathrm{CO}_{2}$ absorption. In the investigated AAPILs, the $\mathrm{CO}_{2}$ absorption capacity was as follows: P[VBIm][Arg] > P[VBIm][Lys] > P[VBIm] $[$ His $]>$ $\mathrm{P}[$ VBIm $][$ Pro $]>\mathrm{P}[\mathrm{VBIm}][\mathrm{Gly}]>\mathrm{P}[\mathrm{VBIm}][\mathrm{Val}]>\mathrm{P}[\mathrm{VBIm}][$ Ala $]$. The accessibility of available more amine groups in AAPIL with arginate anion is the main factor for the high $\mathrm{CO}_{2}$ absorption capacity. Also, chemical absorption of $\mathrm{CO}_{2}$ via carbamate formation was corroborated by FT-IR spectroscopy.
\end{abstract}

Keywords: AAPILs; Thermodynamics; Absorption; $\mathrm{CO}_{2}$

*Corresponding Author, 
E-mail address:nnorani1@yahoo.com

\section{Introduction}

The emission of carbon dioxide from the combustion of natural gas, petroleum, and coal is the major reason of global warming. Therefore, carbon dioxide capture and conversion are one of the major environmental concerns, in the past decade which has attracted the main attention from the scientific society [1-3]. Carbon capture and storage (CCS) is an efficient procedure to absorb carbon dioxide from such industries [4]. Various technologies for $\mathrm{CO}_{2}$ capture are applied containing, membrane separation, chemical absorption, physical adsorption, and hybrid applications of these. Amongst the prevalent technologies of $\mathrm{CO}_{2}$ uptake, chemical absorption with alkanolamines or their combinations such as n-methyl diethanolamine (MDEA), monoethanolamine (MEA), and diethanolamine (DEA) is one of the efficient technologies for $\mathrm{CO}_{2}$ capture. Nevertheless, these absorbents are facing some limitations such as solvent loss, the amines degradation at high temperature in the process of regeneration, and the amines corrosion [5]. Therefore, it seriously affects the progress of the environmental process. Hence, novel materials or solvents such as ionic liquids (ILs), membranes, and solid adsorbents as good alternatives for efficacious capture of $\mathrm{CO}_{2}$ have offered. Ionic liquids (ILs) have been attracted considerable attention as alternative $\mathrm{CO}_{2}$ absorbents owing to their special characteristics such as strong solubility power, high thermal, high polarity, chemical stability, negligible volatility, and high affinity to acid gases [6-9]. Designing the physical and chemical properties of IL by selecting the favorable cations and anions can be caused by to increase in the $\mathrm{CO}_{2}$ absorption capacity in ILs [10]. Davis et al. [11] investigated the $\mathrm{CO}_{2}$ uptake with a new task-specific ionic liquid and indicate that the interactions of chemical was major effective for $\mathrm{CO}_{2}$ absorption and molar capture of $\mathrm{CO}_{2}$ per mole of ionic liquid approach 0.5. Khanna et al [12] reported 
absorption capacity in amino acid-based ILs with 1-butyl 3-methyl imidazolium cation and they indicate that maximum $\mathrm{CO}_{2}$ absorption with $0.62 \mathrm{~mol} \mathrm{CO} / \mathrm{mol} \mathrm{IL}$ and $0.48 \mathrm{~mol} / \mathrm{mol}$ are related to $[\mathrm{bmim}][\mathrm{Arg}]$ and [bmim][Lys], respectively. Saravanamurgan et al [13] have surveyed $\mathrm{CO}_{2}$ absorption onto amino acid ionic liquids with ammonium cation and various anions containing lysinate, histidinate, asparaginate, and glutaminate. They have proposed that these ILs increment $\mathrm{CO}_{2}$ absorption capacity via chemisorptions process. Despite these advantages, amino acid ionic liquids face problems such as having lower thermal stability than common ILs. The first time, Tang et al. [14] were investigated $\mathrm{CO}_{2}$ adsorption capacities onto polymerized ionic liquids (PILs) and reveal that PILs had further $\mathrm{CO}_{2}$ capture than other ILs. Also, they indicated that $\mathrm{P}[\mathrm{VBTMA}]\left[\mathrm{BF}_{4}\right]$ and $\mathrm{P}[\mathrm{MATMA}]\left[\mathrm{BF}_{4}\right]$ have a capacity of $10.22 \mathrm{~mol} \%$ and $7.99 \mathrm{~mol} \%$ respectively, while their monomers, not observe $\mathrm{CO}_{2}$ capture due to having structures of crystalline in low pressure [15]. Wilfred et al [16] have been reported that the $\mathrm{CO}_{2}$ solubility in P[VBTMA][Cl] $\sim 0.188 \mathrm{~mol} \mathrm{CO}_{2} /$ mole PIL further than the monomer, [VBTMA][Cl] $\sim 0.07 \mathrm{~mol}$ $\mathrm{CO}_{2} /$ mole IL. Therefore, the $\mathrm{CO}_{2}$ uptake capacity in PILs is higher than their monomeric state; this behavior is related to their size and free volume which affects their physical adsorption [17]. Polymerized ionic liquids are solid and easily controllable compared to the liquid state. The $\mathrm{CO}_{2}$ absorption capacity relates to the polymer backbone, polycation sort, and anion type [14]; hence the PILs properties are modified by exchanging the polycation-anion pair [18]. In this study, $\mathrm{CO}_{2}$ absorption in AAPILs with vinyl imidazolium-cation and aminate-anion was investigated. The seven AAPILs: poly (1-butyl-3-vinylimidazolium glycinate), P[VBIm][Gly], poly (1-butyl3-vinylimidazolium alaninate), P[VBIm][Ala], poly (1-butyl-3-vinylimidazolium valinate), P[VBIm][Val], poly (1-butyl-3-vinylimidazolium prolinate) P[VBIm][Pro], poly (1-butyl-3vinylimidazolium hisdinate), P[VBIm][His], poly (1-butyl-3-vinylimidazolium lysinate), 
P[VBIm][Lys], and poly (1-butyl-3-vinylimidazolium arginate), P[VBIm][Arg] were synthesized by the neutralization technique and characterized using proton nuclear magnetic resonance ( $\left.{ }^{1} \mathrm{HNMR}\right) . \mathrm{CO}_{2}$ absorption in AAPILs was evaluated in temperature range $288.15-308.15 \mathrm{~K}$ and pressures up to 5 bar using quartz crystal microbalance (QCM). The measured $\mathrm{CO}_{2}$ absorption was fitted by the reaction equilibrium thermodynamic model (RETM) based on the absorption mechanism presuming the complexes formation. The corresponding thermodynamic parameters, contain Henry's law constant $(H)$ and reaction equilibrium constant $\left(K_{x}\right)$ were calculated. The molar enthalpy the $\mathrm{CO}_{2}$ solution was determined from the absorption data and thermodynamics theory. The chemical adsorption of $\mathrm{CO}_{2}$ due to formation of carbamate has been corroborated by spectroscopy of fourier transform infrared (FT-IR). The effect of anion in the poly(ionic liquid)s on the $\mathrm{CO}_{2}$ absorption capacity has been surveyed.

\section{Experimental Section}

\section{Materials}

1-vinylimidazole (>99\% wt\%), L-Glycine (Gly), $\alpha$-Alanine (Ala), L-Proline (Pro), L-Valine (Val), L-Histidine (His), L-Lysine (Lys), and L-Arginine (Arg) were provided from Sigma Aldrich products (purity $\geq 99.99 \mathrm{wt} \%$ ). 2,2'-Azobis (2-ethylpropionitrile) (AIBN) as initiator, 1Bromobutane ( $>99 \%$ wt \%), Dimethylformamide (purity $>0.99 \mathrm{wt} \%$ ), Ethyl acetate (purity $>0.99$ wt \%), acetone and Ethanol (purity $\geq 99.99 \mathrm{wt} \%$ ) were purchased from Merck. The molecular structure of amino acids and their properties are illustrated in Table $1 . \mathrm{CO}_{2}$ (purity $\geq 99.99 \mathrm{wt} \%$ ) was used in gas absorption experiments.

\section{Synthesis}

\section{Synthesis of Ionic Liquid}


The ionic liquid, 1-butyl-3-vinyl imidazolium bromide, [VBIm][Br] was synthesized by the reported methods in the literatures $[19,20]$ via direct alkylation of 1-vinyl imidazole by an excess value of 1-bromobutane refluxed at $350 \mathrm{~K}$ for 48 hours under an argon atmosphere. Then the obtained product was extracted by ethyl acetate. To eliminate ethyl acetate and 1-bromobutane, the product was dried at $318 \mathrm{~K}$ by a rotary evaporator. To assurance the elimination of remaining ethyl acetate and 1-bromobutane, the formed IL was exposed at high vacuum condition for at least $12 \mathrm{~h}$. The ionic liquid was utilized after vacuum desiccated for $72 \mathrm{~h}$ to eliminate the moisture. The water content of ionic liquid was determined with Karl-Fischer titrator (720-KSSMetrohm Herisau, Switzerland) and it was less than 0.01 in mass fraction. The synthesized ionic liquid were characterized by ${ }^{1} \mathrm{HNMR}$ (Bruker Av-400, Germany) and FT-IR.

${ }^{1} \mathrm{H}$ NMR (400 MHz, $\left.\mathrm{CDCl}_{3}, \delta_{\mathrm{H}}, \mathrm{ppm}\right): 10.95$ (s, 1H, NCHN), 7.89 (t, 1H, NCHC), 7.63(t, 1H, CCHN), 7.50 (dd, 1H, $\left.\mathrm{CH}_{2} \mathrm{CHN}\right), 5.95$ (dd, 1H, HCHCHN), 5.36 (dd, 1H, HCHCHN), 4.38 (t, 2H, $\mathrm{NCH}_{2} \mathrm{C}$ ), $1.91\left(\mathrm{~m}, 2 \mathrm{H}, \mathrm{CH}_{2} \mathrm{CH}_{2} \mathrm{CH}_{2}\right), 1.37$ (m, 2H, $\left.\mathrm{CH}_{2} \mathrm{CH}_{2} \mathrm{CH}_{3}\right), 0.96$ (t, 3H, $\mathrm{CH}_{2} \mathrm{CH}_{3}$ ). FTIR $\left(v_{\max }, \mathrm{cm}^{-1}\right): 3145,3072(\mathrm{CH}$ imidazole ring $), 2964,2935,2870(\mathrm{CH}$ aliph$), 1652(\mathrm{C}=\mathrm{C})$, 1571, 1551 (CH imidazole ring).

\section{Synthesis of amino acid-based polyionic liquids (AAPILs)}

To synthesis of poly(1-butyl-3-vinylimidazolium aminate), P[VBIm][AA] with different aminates (glycinate $\left[\mathrm{Gly}^{-}\right.$, alaninate $[\mathrm{Ala}]^{-}$, valinate $[\mathrm{Val}]^{-}$, prolinate $[\mathrm{Pro}]^{-}$, hisdinate $[\mathrm{His}]^{-}$, lysinate $[\mathrm{Lys}]^{-}$, and arginate $[\mathrm{Arg}]^{-}$), firstly, poly(1-butyl-3-vinylimidazolium bromide), $\mathrm{P}[\mathrm{VBIm}][\mathrm{Br}]$ was synthesized using refluxing the mixture of $[\mathrm{BVIm}][\mathrm{Br}](0.131 \mathrm{~mol})$ and AIBN $(0.152 \mathrm{mmol})$ in DMF $(50 \mathrm{~mL})$ at $338 \mathrm{~K}$ for $24 \mathrm{~h}$ under a argon atmosphere [21]. $\mathrm{P}[\mathrm{VBIm}][\mathrm{Br}]$ was separated via precipitation in acetone and filtering the synthesized product. Poly(1-butyl-3-vinyl imidazolium bromide) was dried at high vacuum condition for at least $12 \mathrm{~h}$. 
P[VBIm] $[\mathrm{Br}]$ characterized using the ${ }^{1} \mathrm{HNMR}$ and FT-IR. ${ }^{1} \mathrm{HNMR}$ and FT-IR spectra of $\mathrm{P}[\mathrm{VBIm}][\mathrm{Br}]$ is displayed in the supplementary information (Fig.S1 and S2). Then, poly(1butyl-3-vinyl imidazolium hydroxide) (P[VBIm][OH]) was procured from aqueous solution of $\mathrm{P}[\mathrm{VBIm}][\mathrm{Br}]$ through anion exchange resin. The exchange of bromide anion with hydroxide was carried out in the glass column contains ion exchange resin and residual $\mathrm{Br}^{-}$was tested with silver nitrate $\left(\mathrm{AgNO}_{3}\right)$. Prepared P[VBIm] $[\mathrm{OH}]$ aqueous solution was added drop wise to excess equimolar aqueous L-Glycine, $\alpha$-Alanine, L-Valine, L-Proline, L-Histidine, L-Lysine, or LArginine (1.2 equivalent) solutions, and stirred at ambient temperature for $48 \mathrm{~h}$. Then water amount was removed with a rotary evaporator for at least $8 \mathrm{~h}$ at $352 \mathrm{~K}$. The unreacted amino acids were eliminated via precipitation in absolute ethanol. The synthesis AAPILs evaporated to remove ethanol undergo a vacuum for $5 \mathrm{~h}$ at $338 \mathrm{~K}$. The water quantity of the AAPILs was determined about 0.01 in mass fractions using a Karl-Fischer titrator. ${ }^{1} \mathrm{H}$ NMR spectra of AAPILs are represented in the supplementary information (Figs. S3-S9).

\section{Characterization of aminate anion AAPILs}

To characterize the AAPILs after $\mathrm{CO}_{2}$ absorption was used a spectrometer of FT-IR (Bruker, Tensor 27). Densities of the AAPILs were measured using the flotation method at $298.15 \mathrm{~K}$ in mixtures of chloroform and acetone. The mixture of the solution was adjusted so that the AAPIL remained suspended throughout. The density of the solutions was determined with a density analyzer (DSA5000, Anton Paar).

\section{Gas absorption apparatus}

QCM sensor was applied for gas absorption measurement. The cell of solubility entails an 8 $\mathrm{MHz}$ AT-cut quartz crystal utilized in the electrical oscillator circuit. Absorption apparatus 
performance has been mentioned in the prior papers by authors in details [22-26]. The quantity of absorbed $\mathrm{CO}_{2}, n_{\mathrm{CO}_{2}} / n_{\text {monomer }}\left(\mathrm{mol}_{\mathrm{CO}_{2}} \cdot \mathrm{mol}_{\text {monomer }}^{-1}\right)$ was computed as follows:

$\frac{n_{\mathrm{CO}_{2}}}{n_{\text {monomer }}}=\frac{\Delta F_{S}}{\Delta F_{C}} \times \frac{M_{\text {monomer }}}{M_{\mathrm{CO}_{2}}}$

where $\Delta F_{C}$ frequencies difference between the coated and the uncoated crystal. $\Delta F_{S}$ is the frequencies difference between the PILs covered crystal under vacuum and the PILs covered crystal after $\mathrm{CO}_{2}$ adsorption.

\section{Thermodynamic model}

The data of absorption isotherm were fitted by the "deactivated model" offered by Goodrich et al. [27] to describe the physical and chemical absorption of $\mathrm{CO}_{2}$ in AAPILs. This model, the $\mathrm{CO}_{2}$ amount absorbed in the AAPIL considers as the sum of two contribution (physical and chemical absorption) and assumes that only 1:1 reaction happens and less than $100 \%$ of the ionic liquids are allowed to react with $\mathrm{CO}_{2}$. The mechanism of $\mathrm{CO}_{2}$ physically and chemically absorption expressed as follows:

$$
C O_{2(g)} \leftrightarrow C O_{2(l)}
$$

$\mathrm{AAIL}_{(l)}+\mathrm{CO}_{2(l)} \stackrel{K_{x}}{\longrightarrow} \mathrm{CO}_{2}-\mathrm{AAIL}_{(l)}$

Henry's law is related to $\mathrm{CO}_{2}$ physically absorption as follows:

$p_{\mathrm{CO}_{2}}=H x_{\mathrm{CO}_{2(l)}}$

where $x_{C_{2(l)}}$ is the physically absorption value, $p_{\mathrm{CO}_{2}}$ is the partial pressure of $\mathrm{CO}_{2}$ in bar, $\mathrm{H}$ is the $\mathrm{CO}_{2}$ Henry's law constant in the AAPILs in bar. The adsorbed $\mathrm{CO}_{2}$ undergoes a reaction after physically absorption and the value of chemically absorbed $\mathrm{CO}_{2}$ in the AAPILs is shown using the reaction equilibrium constant $\left(K_{x}\right)$ : 


$$
K_{x}=\frac{x_{\mathrm{CO}_{2}-\text { monomer }_{(i)}}}{x_{\text {monomer }(l)}} x_{\mathrm{CO}_{2(l)}}
$$

The total mole of the AAPIL monomers is the sum of the moles of the AAPIL monomer, $\mathrm{CO}_{2}$-monomer complex and the deactivated the AAPIL monomers. The mole of the deactivated AAPIL monomer indicates the mole of the AAPIL monomers that does not react with $\mathrm{CO}_{2}$.

$n_{\text {monomer }}^{0}=n_{\text {monomer }}+n_{\mathrm{CO}_{2} \text {-monomer }}+n_{\text {deactivatel }- \text { monomer }}$

The total mole of $\mathrm{CO}_{2}$ in the AAPILs is the total absorbed $\mathrm{CO}_{2}$ both physically and the chemically reacted as AAPIL- $\mathrm{CO}_{2}$ complex,

$$
n_{\mathrm{CO}_{2}}=n_{\mathrm{CO}_{2(l)}}+n_{\mathrm{CO}_{2}-\text { monome }(l)}
$$

The total mole of $\mathrm{CO}_{2}$ in the AAPIL calculated from solving Eqs. (4), (5) and (6) as follows:

$$
\frac{n_{\mathrm{CO}_{2}}}{n_{\text {monomer }}^{0}}=\frac{p_{\mathrm{CO}_{2}}}{H-p_{\mathrm{CO}_{2}}}+\frac{K_{x} p_{\mathrm{CO}_{2}}}{H+K_{x} p_{\mathrm{CO}_{2}}}\left(1-\frac{n_{\text {deactivatel-monomer }}}{n_{\text {monomer }}^{0}}\right)
$$

This model assumes that not all of the AAPIL monomers are available for reacting with the $\mathrm{CO}_{2}$ molecule and $C=1-\frac{n_{\text {deactivated-monomer }}}{n_{\text {monomer }}^{0}}$ is considered as an experimental constant.

\section{Result and Discussion}

\section{Physical Characterization of AAPILs}

AAPILs' physical characterization is indicated in Table 2. Table 2 indicates the densities of AAPILs at temperature $298.15 \mathrm{~K}$. The data imply that the structures of aminate-anion influence the densities of the PILs notably. It has been observed that the densities incremented as [Hist] > $[$ Pro $]>[\mathrm{Lys}]>[\mathrm{Gly}]>[\mathrm{Ala}]>[\mathrm{Arg}]>[\mathrm{Val}]$. Lengthen the alkyl side chains of $[\mathrm{AA}]$ increments the free volume of the PILs thereby decrementing their density. Moreover, the AAPILs with 
aromatic rings [His] and [Pro] have a relatively high density compared to the other anions. The present AAPILs reveal a similar trend in densities as reported for AAILs having the same $[\mathrm{AA}]^{-}$ anions with different cations [28-30].

\section{Characterization of aminate $\mathrm{P}[\mathrm{VBIm}][\mathrm{AA}] \mathrm{s}$ after $\mathrm{CO}_{2}$ absorption}

Obtained FT-IR spectra of the AAPILs: P[VBIm][Gly], P[VBIm][Ala], P[VBIm][Val], $\mathrm{P}[\mathrm{VBIm}][\mathrm{Pro}], \mathrm{P}[\mathrm{VBIm}][\mathrm{His}], \mathrm{P}[\mathrm{VBIm}][\mathrm{Arg}]$, and $\mathrm{P}[\mathrm{VBIm}][\mathrm{Lys}]$ after and before $\mathrm{CO}_{2}$ absorption are illustrated in Fig. 1. The reaction between $\mathrm{CO}_{2}$ and aminate anion of monomer produced carbamate. The characteristic FT-IR peaks related to $\mathrm{C}=\mathrm{O}$ of the $\mathrm{COO}^{-}$anion, which generally overlaps with $-\mathrm{NH}$ from the amino acids, were observed at $1550-1580 \mathrm{~cm}^{-1}$ with high intensity. Broad signals at $2825-3562 \mathrm{~cm}^{-1} \mathrm{~cm}^{-1}$ related to $-\mathrm{NH}$ in secondary amides that resulted from $\mathrm{CO}_{2}$ reacting with $\mathrm{NH}_{2}$ and the peak of the $\mathrm{C}-\mathrm{N}$ stretch was indicated at $1480 \mathrm{~cm}^{-1}$. The peak with strong intensity at $1640-1650 \mathrm{~cm}^{-1}$ corresponding to the carbamate species. The reaction between $\mathrm{CO}_{2}$ and $\mathrm{NH}_{2}$ was confirmed in AAPILs. These functional groups confirmed the physical and chemical absorption in AAPILs.

\section{Effect of pressure on $\mathrm{CO}_{2}$ absorption}

In this study, we investigated the absorption of $\mathrm{CO}_{2}$ in the AAPILs with different aminates glycinate $[\mathrm{Gly}]^{-}$, alaninate $[\mathrm{Ala}]^{-}$, valinate $[\text {Vall }]^{-}$, prolinate $\left[\mathrm{Pro}^{-}\right.$, hisdinate $[\mathrm{His}]^{-}$, lysinate $[\mathrm{Lys}]^{-}$, and arginate $[\mathrm{Arg}]^{-}$at temperatures range of $288.15-308.15 \mathrm{~K}$ and pressures up to 5 bar. The absorption data of $\mathrm{CO}_{2}$ in the AAPILs are reported in Table 3. To survey the effect of temperature and pressure, $\mathrm{CO}_{2}$ absorption isotherms of the AAPILs with different aminates at different temperatures and pressures are displayed in Fig. 2. Fig. 2 indicates the dependence of absorption on pressure and temperature. $\mathrm{CO}_{2}$ absorption in the AAPILs was incremented with increment in pressure and decrement in temperature. $\mathrm{CO}_{2}$ absorption isotherms of the AAPILs 
have a non-linear tendency and the $\mathrm{CO}_{2}$ absorption rises a lot in the low-pressures while it enhancements nearly linearly in the higher pressures which represents more sensitivity of absorption to pressure in the low-pressure range. At low pressure, an increase of $\mathrm{CO}_{2}$ absorption is related to the chemical absorption process, and the more increment at higher pressure corresponding to physical adsorption [31]. This behavior indicates that the $\mathrm{CO}_{2}$ absorption in AAPILs at high pressure combines the chemical absorption and physical adsorption characteristic [32]. Brennecke et al. [33] reported the isotherms are subdivided into two distinct sections: a sharp increment at low pressures due to chemical absorption and a marginal increment in absorption capacity at higher pressures which is ordinary for physical absorption. Nonetheless, it was shown that the most of the capture was due to chemical absorption which results are in good agreement with our results reported. Also, a similar results are published for amino acid-based ILs, Raja Shahrom et al [34] reported that at low pressure, a high capture of $\mathrm{CO}_{2}$ is owing to the chemical absorption process and the more increment at higher pressure is owing to physical adsorption. This behavior indicates that the $\mathrm{CO}_{2}$ capture by AAPILs at high pressure merges the characteristics of physical adsorption as well as chemical absorption.

\section{Effect of anion on $\mathrm{CO}_{2}$ absorption}

To survey the effect of anion, a comparison of $\mathrm{CO}_{2}$ absorption in P[VBIm][Gly], P[VBIm][Ala], $\mathrm{P}[\mathrm{VBIm}][$ Val], P[VBIm][Pro], P[VBIm][His], P[VBIm][Lys], and P[VBIm][Arg] is represented in Fig. 3. Fig. 3 demonstrates that $\mathrm{CO}_{2}$ absorption rate of [Arg] with $1.05 \mathrm{~mol} / \mathrm{mol}$ is higher, followed by [Lys], [Hist] have less $\mathrm{CO}_{2}$ capacity with $0.95 \mathrm{~mol} / \mathrm{mol}$ and $0.79 \mathrm{~mol} / \mathrm{mol}$, respectively. The [Arg] anion contains four amine groups; therefore, a higher chance for $\mathrm{CO}_{2}$ is available to react with four accessible amine sites. [Lys] has the $\mathrm{CO}_{2}$ absorption capacity lower than [Arg] and this behavior may be attributed to two primary amine groups in [Lys]. [His] 
contains a pentagonal ring with one secondary and one primary amine groups; due to steric hindrance and low efficacies of secondary amine group [His] allocates third place after [Arg] and [Lys] (Fig. 3). [Pro], [Gly], [Ala], and [Val] have a lone one amine group and have a $\mathrm{CO}_{2}$ capacity with $0.63,0.60,0.53$, and $0.50 \mathrm{~mol} / \mathrm{mol}$ respectively. The amine group number and alkyl chain length of cation are two main factors that effect on the process of $\mathrm{CO}_{2}$ absorption. The results indicate that the effect of the amine group's number is more important than the alkyl chain length in the $\mathrm{CO}_{2}$ absorption process. The remainder of the AAPILs ([Gly], [Ala], [Val]) have one primary amine group and a nonpolar aliphatic side chain. All these AAPILs display less or more similar capacities of $\mathrm{CO}_{2}$ absorption as illustrated in Fig. 3. The obtained results are similar to available reports in the literature for monomeric (AAILs) and polymeric (AAPILs). Raja Shahrom et al [34] were investigated $\mathrm{CO}_{2}$ absorption in forms of AAILs and AAPILs for eight anions [Gly], [Ala], [Ser], [Tau], [Arg], [Lys], [Hist], and [Pro] with ammonium based, [VBTMA], cation. They indicate that [VBTMA][Arg] gave the highest capacity of $\mathrm{CO}_{2}$ absorption with $0.83 \mathrm{~mol} / \mathrm{mol}$ and [VBTMA][Ala] has the least capacity of $\mathrm{CO}_{2}$ absorption with $0.29 \mathrm{~mol} / \mathrm{mol}$. Also, they reveal P[VBTMA][Arg] and P[VBTMA][Lys] have higher $\mathrm{CO}_{2}$ absorption with $1.14 \mathrm{~mol} / \mathrm{mol}$ and $1.13 \mathrm{~mol} / \mathrm{mol}$ respectively, P[VBTMA][Ala] has lowest absorption with $0.56 \mathrm{~mol} / \mathrm{mol}$. Sistla et al. [12] have been investigated various AAILs and observed that $\mathrm{CO}_{2}$ absorption capacities were as order: [bmim][Arg] $(0.62 \mathrm{~mol} \mathrm{CO} / \mathrm{mol} \mathrm{IL})>$ [bmim][Lys] $\left(0.48 \mathrm{~mol} \mathrm{CO}_{2} / \mathrm{mol} \mathrm{IL}\right)>\left[\right.$ bmim][His] $\left(0.45 \mathrm{~mol} \mathrm{CO}_{2} / \mathrm{mol} \mathrm{IL}\right)>[$ bmim][Pro] $(0.32$ mol CO $2 / \mathrm{mol} \mathrm{IL).} \mathrm{Santiago} \mathrm{et} \mathrm{al.} \mathrm{[35]} \mathrm{have} \mathrm{been} \mathrm{reported} \mathrm{that} \mathrm{[bmim][Met]} \mathrm{and} \mathrm{[bmim][Gly]}$ present similar and the highest $\mathrm{CO}_{2}$ sorption capacity $\left(0.035 \mathrm{~g} \mathrm{CO}_{2} / \mathrm{g} \mathrm{IL}\right)$, while $[\mathrm{bmim}][$ Pro] shows lower one $\left(0.020 \mathrm{~g} \mathrm{CO}_{2} / \mathrm{g} \mathrm{IL}\right)$. Also, the values of $H$ and $K_{x}$ increase in the order of [Arg] $>[\mathrm{Lys}]>[\mathrm{His}]>[\mathrm{Gly}]>[\mathrm{Ala}]>[\mathrm{Val}]>[$ Pro $]$. In Eq. (8) the primary term and second term 
indicate physical absorption and chemical absorption, respectively. The high quantities of the chemical reaction constant $\left(K_{x}\right)$ reveals that chemical absorption has seven contribution in the $\mathrm{CO}_{2}$ absorption process while the higher values of Henry constant $(H)$ reveals that physical absorption has low contribution in the $\mathrm{CO}_{2}$ absorption process in AAPILs. Therefore, the high values of $K_{x}$ represent a strong driving force in the formation complex of the AAPILs with $\mathrm{CO}_{2}$.

\section{Parameters of thermodynamic model}

To achieve a deep understanding of the $\mathrm{CO}_{2}$ absorption phenomenon in AAPILs, it is necessary to assess the contributions of chemical and physical individually. For this purpose, the experimental adsorption data were fitted by Eq. (8) by the non-linear regression and the thermodynamic parameters were calculated. The calculated experimental absorption data represent that the $\mathrm{CO}_{2}$ absorption in the AAPILs is well correlated by Eq. (8) and $\mathrm{CO}_{2}$ is absorbed both physically and chemically. In the $\mathrm{CO}_{2}$ absorption process, the values of Henry's law constant $(H)$ and the reaction equilibrium constants $\left(K_{x}\right)$ are related to the $\mathrm{CO}_{2}$ absorption capacity. The physical absorption is related to Henry's law constant $(H)$, and the reaction equilibrium constant $\left(K_{x}\right)$ is related to the chemical absorption. So, these parameters obtained by fitting the experimental absorption data and then evaluate the absorbent for the $\mathrm{CO}_{2}$ absorption process. The fitted parameters Henry's constant $(H)$, the reaction equilibrium constant $\left(K_{x}\right)$, experiment constant $(C)$, the correlation coefficient $\left(R^{2}\right)$, and absolute average relative deviation $(A A R D)$ are summarized in Table 4. The results manifest that the correlation coefficients $R^{2}$ higher than 0.999 which implies to the applicably of the suggested model. According to Table 4 , $H$ values increment by incrementing temperature, while $K_{x}$ values decremented at all the AAPILs. Also, the values of $H$ and $K_{\mathrm{x}}$ increase in the order of [Arg] $>$ [Lys] $>$ [His] $>$ [Pro] $>$ $[\mathrm{Gly}]>[\mathrm{Val}]>[\mathrm{Ala}]$. In Eq. (8) the primary term and second term indicate physical absorption 
and chemical absorption, respectively. The high values of Henry constant $(H)$ is related to the low physical control and the low values of the chemical reaction constant $\left(K_{x}\right)$ is attributed to the chemical contribution.

\section{Enthalpy of dissolution and reaction}

The effect of temperature on $\mathrm{CO}_{2}$ absorption is attributed to the molar enthalpy of absorption: [36-38]:

$$
\begin{aligned}
\Delta \mathrm{H}_{e q} & =-R\left(\frac{\partial \ln K_{X}}{\partial(1 / T)}\right) \\
\Delta \mathrm{H}_{s o l} & =R\left(\frac{\partial \ln H}{\partial(1 / T)}\right)
\end{aligned}
$$

The investigation demonstrates that increase of the temperature decrements the value of dissolved $\mathrm{CO}_{2}$ which indicating the physical absorption of gas in the mixture and corresponding to the physical contribution ( $H$ values). Moreover, an rising temperature reduces $\mathrm{CO}_{2}$ chemical absorption, i.e. $K_{\mathrm{x}}$ reduces at high temperatures which this behavior is in well agreement with usual exothermic reactions expressed in $\mathrm{CO}_{2}$ absorption in ILs $[39,40]$. The values of enthalpy were assessed from plots of $\mathrm{H}_{\mathrm{CO}_{2}}$ and $K_{\mathrm{x}}$ against $T$, and the obtained data are reported in Table 5 . The negative quantities of chemical reaction enthalpy $\left(\Delta H_{\mathrm{eq}}\right)$ and physical dissolution enthalpy ( $\Delta H_{\text {sol }}$ ) expose that the $\mathrm{CO}_{2}$ absorption process in the AAPILs is exothermic.

\section{Regeneration efficiency of the AAPILs}

Regeneration is one of the important factors to assess absorption efficiency. To evaluate the capacity of reuse, three cycles of $\mathrm{CO}_{2}$ absorption/desorption trial of P[VBIm][Arg] investigated and plotted in Fig. 4. Fig. 4 demonstrates that the yield of the P[VBIm][Arg] is approximately constant after three consecutive recycles. For the regeneration experiment, $\mathrm{CO}_{2}$ absorption is tested at 1 bar and $293.15 \mathrm{~K}$, and desorption under vacuum at a temperature of $293.15 \mathrm{~K}$ and 90 
min to omit $\mathrm{CO}_{2}$. The absorption/desorption amount represents that $\mathrm{CO}_{2}$ was perfectly omitted in 90 min and the absorption amount is stable in three cycles. The reduction in $\mathrm{CO}_{2}$ absorption capacity of the regenerated P[VBIm] Arg] was apperceived to be about $1 \%$ in the three cycles of regeneration in comparison to the fresh sample. This behavior indicates that the P[VBIm][Arg] is regenerable and stable under practicable situations of regeneration. The $\mathrm{CO}_{2}$ absorption quantities of P[VBIm][Arg] are obtained $0.587,0.585,0.585,0.583,0.599$ and 0.599 in six sequential cycles of absorption/desorption and the regeneration yield P[VBIm][Arg] are 97.58\%, respectively after three consecutive cycle absorption/desorption.

\section{Conclusions}

$\mathrm{CO}_{2}$ absorption in the AAPILs has been evaluated in the temperature range $288.15-308.15 \mathrm{~K}$ and pressures up to 5 bar by QCM. The reaction equilibrium thermodynamic model has been utilized to assess chemical and physical absorption of $\mathrm{CO}_{2}$ in the AAPILs. The outcomes reveal that the $\mathrm{CO}_{2}$ absorption in the AAPILs at low pressures is generally attributed to chemical absorption. Various aminates with primary and secondary amines were considered to study the effect of the amino acid anion nature on $\mathrm{CO}_{2}$ absorption capacity. Among of AAPILs investigated, $\mathrm{P}[\mathrm{VBIm}][\mathrm{Arg}]$ has the highest $\mathrm{CO}_{2}$ absorption capacity and $\mathrm{P}[\mathrm{VBIm}][\mathrm{Val}]$ has the lowest $\mathrm{CO}_{2}$ absorption capacity. This phenomenon reveals that the AAPILs with several amine sites represent higher $\mathrm{CO}_{2}$ absorption capacity than the AAPILs with one primary amine group. The FT-IR spectroscopy of the $\mathrm{CO}_{2}$ absorbed AAPILs indicates the formation of carbamate species. Also, the physical dissolution enthalpy and the chemical reaction show that the $\mathrm{CO}_{2}$ absorption process in the AAPILs is exothermic. 


\section{Statements and Declaration}

The authors declare that they have no known competing financial and non financial interest so personal relationships that could have appeared to influence the work reported in this paper.

\section{References}

1. Firaha DS, Kirchner B (2016) Tuning the carbon dioxide absorption in amino acid ionic liquids, ChemSusChem. 9:1-10.

2. Lei Z, Dai C, Chen B(2014) Gas solubility in ionic liquids, Chem. Rev. 114: 1289-1326.

3. Pan M, Wang C (2015) Recent advances in $\mathrm{CO}_{2}$ capture by functionalized ionic liquids, advances in $\mathrm{CO}_{2}$ capture, sequestration, and conversion, American Chemical Society, Washington, DC, 1194: 341-369.

4. Matter JM, Stute M, Snaebjornsdottir SO, Oelkers EH, Gislason SR, Aradottir ES, Sigfusson B, Gunnarsson I, Sigurdardottir H, Gunnlaugsson E, Axelsson G, Alfredsson HA, WolffBoenisch D, Mesfin K, Taya DFDIR, Hall J, Dideriksen K, Broecker WS (2016) Rapid carbon mineralization for permanent disposal of anthropogenic carbon dioxide emissions, Science 352: $1312-1314$.

5. Rochelle GT (2009) Amine scrubbing for $\mathrm{CO}_{2}$ capture, Science 325 : 1652-1654.

6. Cui GK, Wang JJ, Zhang SJ (2016) Active chemisorption sites in functionalized ionic liquids for carbon capture, Chem. Soc. Rev. 45 : 4307-4339.

7. Earle MJ, Esperanca J, Gilea MA, Lopes JNC, Rebelo LPN, Magee JW, Seddon KR, Widegren JA (2006) The distillation and volatility of ionic liquids, Nature, $439: 831-834$.

8. MacDowell N, Florin N, Buchard A, Hallett J, Galindo A, Jackson G, Adjiman CS, Williams CK, Shah N, Fennell P (2010) An overview of $\mathrm{CO}_{2}$ capture technologies, Energy Environ. Sci. 3:1645-1669. 
9. Bara JE, Camper DE, Gin DL, Noble RD (2010) Room-temperature ionic liquids and composite materials: platform technologies for $\mathrm{CO}_{2}$ capture, Acc. Chem. Res. 43: 152-159.

10. Vidal L, Riekkola ML, Cannals A (2012) Ionic liquid-modified materials for solid-phase extraction and separation : a review, Anal. Chim. Acta $715: 19-41$.

11. Bates ED,. Mayton RD, Ntai I, Davis JH (2002) $\mathrm{CO}_{2}$ capture by a Task-Specific ionic liquid. J. Am. Chem. Soc., 124 : 926-927.

12. Sistla YS, Khanna A (2014) $\mathrm{CO}_{2}$ absorption studies in amine functionalized ionic liquids, J. Ind. Eng. Chem. 20 : 2497-2509.

13. Saravanamurugan Sh., Kunov-Kruse AJFR, Riisager A (2014) Amine-Functionalized Amino acid-based ionic liquids as efficient and high-capacity absorbents for $\mathrm{CO}_{2}$, ChemSusChem. 7 : 897-902.

14. Tang J, Sun W, Tang H, Radosz M, Shen Y (2005) Enhanced $\mathrm{CO}_{2}$ Absorption of Poly(ionic liquid)s, Macromolecules, $38: 2037-2039$.

15. Tang J, Tang H, Sun W, Radosz M, Shen Y(2005) Low-pressure $\mathrm{CO}_{2}$ sorption in ammonium-based poly(ionic liquid)s, Polymer, 46 : 12460-12467.

16. Raja Shahrom M Sh, Wilfred C D, Ziyada Taha A Kh (2016) $\mathrm{CO}_{2}$ capture by task specific ionic liquids (TSILs) and polymerized ionic liquids (PILs and AAPILs), J. Mol. Liq. 219 : 306312

17. Yu CH (2012) A Review of $\mathrm{CO}_{2}$ Capture by Absorption and Adsorption, Aerosol and Air Quality Research.

18. Privalova EI, Karjalainen E, Nurmi M, Maki-Arvela P, Eranen K, Tenhu H, Murzin D Yu, Mikkola JP (2013) Imidazolium-based poly(ionic liquid)s as new alternatives for $\mathrm{CO}_{2}$ capture, ChemSusChem. $6: 1500-1509$. 
19. Amajjahe S, Ritter H (2008) Anion Complexation of Vinylimidazolium Salts and Its Influence on Polymerization, Macromolecules, 41: 716-718.

20. Muldoon MJ, Gordon CM (2004) Synthesis of gel-type polymer beads from ionic liquid monomers, J. Polym. Sci. Part A: Polym. Chem. $42: 3865-3869$.

21. Mori H,. Yahagi M, Endo T (2009) RAFT Polymerization of N-vinylimidazolium salts and synthesis of thermoresponsive ionic liquid block copolymers, Macromolecules $42: 8082-8092$.

22. Noorani N, Mehrdad A (2021) Experimental and theoretical study of $\mathrm{CO}_{2}$ sorption in biocompatible and biodegradable cholinium-based ionic liquids, ) Sep. Purif. Technol. 254 : 117609.

23. Noorani N, Mehrdad A (2020) $\mathrm{CO}_{2}$ solubility in some amino acid-based ionic liquids: Measurement,correlation and DFT studies, Fluid Phase Equilibria $517: 112591$.

24. Mehrdad A, Noorani N (2019) Study of $\mathrm{CO}_{2}$ adsorption onto poly(1-vinylimidazole) using quartz crystal microbalance and density functional theory methods. J. Mol. Liq. 291: 111288.

25. Noorani N, Mehrdad A (2019) Adsorption, permeation, and DFT studies of PVC/PVIm blends for separation of $\mathrm{CO}_{2} / \mathrm{CH}_{4}$, J. Mol. Liq. $292: 111410$.

26. Noorani N, Mehrdad A (2020) Modification of PVC with 1-Vinylimidazole for $\mathrm{CO}_{2} / \mathrm{CH}_{4}$ Separation: Sorption, Permeation and DFT Studies, Phys. Chem. Res. 8 : 689-703.

27. Moya C, Alonso-Morales N, Riva J, Morales-Collazo O, Brennecke JF, Palomar J, (2018) Encapsulation of ionic liquids with an aprotic heterocyclic anion (AHAIL) for $\mathrm{CO}_{2}$ capture: preserving the favorable thermodynamics and enhancing the kinetics of absorption, J. Phys. Chem. B $122: 2616-2626$.

28. Sudha Sistla Y, Khanna A (2015) $\mathrm{CO}_{2}$ Absorption Studies in Amino Acid-Anion Based Ionic Liquids.Chem.Eng.J. 273 : 268-276. 
29. Muhammad N, Man Z B, Azmi Bustam M, Abdul Mutalib M I, Wilfred CD, Rafiq S (2011) Synthesis and Thermophysical Properties of Low Viscosity Amino Acid-Based Ionic Liquids. J. Chem. Eng. Data $56: 3157-3162$.

30. Zhang Y, Zhang S, Lu X, Zhou Q, Fan W, Zhang XP (2009) Dual Amino-Functionalised Phosphonium Ionic Liquids for CO2 Capture. Chem. Eur. J. 15 : 3003 - 3011.

31. Goodrich B F, Fuente JCd, Gurkan BE, Zadigian DJ, Price EA, Huang Y, Brennecke J F (2011) Experimental measurements of amine-functionalized anion-tethered ionic liquids with carbon dioxide, Ind. Eng. Chem. Res. $50: 111-118$.

32. Torralba-Calleja E, Skinner J, Gutierrez-Tauste $\mathrm{D}(2013) \mathrm{CO}_{2}$ capture in ionic liquids: a review of solubilities and experimental methods, J. Chem. $2013: 1-16$.

33. Gurkan BE, de la Fuente JC, Mindrup EM, Ficke LE, Goodrich BF, Price EA, Schneider, J.F. Brennecke WF(2010) Equimolar $\mathrm{CO}_{2}$ absorption by anion-functionalized ionic liquids, J. Am. Chem. Soc. $132: 2116-2117$.

34. Raja Shahrom M Sh, Wilfred CD, MacFarlane DR,. Vijayraghavan R, Kait Ch F (2019) Amino acid based poly(ionic liquid) materials for $\mathrm{CO}_{2}$ capture: Effect of anion, J. Mol. Liq. 25 : 644-652.

35. Santiago R, Lemus J, Moya Ch, Moreno D, Alonso-Morales N, Palomar J (2018) Encapsulated Ionic Liquids to enable the practical application of amino acid-based Ionic Liquids in $\mathrm{CO}_{2}$ capture, ACS Sustainable Chem. Eng. $6: 14178-14187$.

36. Chen YF, Zhang YY, Yuan SJ, Ji XY, Liu C, Yang ZH, Lu XH (2016) Thermodynamic study for gas absorption in choline-2-pyrrolidine-carboxylic acid+ polyethylene glycol, J. Chem. Eng. Data 61: 3428-3437. 
37. Huang K, Zhang XM, Hu XB, Wu YT (2016) Hydrophobic protic ionic liquids tethered with tertiary amine group for highly efficient and selective absorption of $\mathrm{H}_{2} \mathrm{~S}$ from $\mathrm{CO}_{2}$, AlChE J. 62: $4480-4490$.

38. Zhou ZM, Jing GH, Zhou LJ(2012) Characterization and absorption of carbon dioxide into aqueous solution of amino acid ionic liquid $\left[\mathrm{N}_{1111}\right][\mathrm{Gly}]$ and 2-amino-2-methyl-1-propanol, Chem. Eng. J. 204 : 235-243.

39. Zoubeik M, Henni A (2014) Experimental and thermodynamic study of $\mathrm{CO}_{2}$ solubility in promising [TF2N and DCN] ionic liquids, Fluid Phase Equilib. $376: 22-30$.

40. Kurnia KA, Harris F, Wilfred CD, Mutalib MIA, Murugesan T (2009) Thermodynamic properties of $\mathrm{CO}_{2}$ absorption in hydroxyl ammonium ionic liquids at pressures of (100-1600) kPa, J. Chem. Thermodyn. 41: 1069-1073.

41. McMurry J (2011) Fundamentals of Organic Chemistry, seventh ed., Cengage Learning, USA, pp. 506-507. 
Table 1. Properties and molecular structures of amino acids [38].

\begin{tabular}{|c|c|c|c|c|}
\hline Amino acid & Abbreviation & Molecule weight & $\mathrm{pK}_{\mathrm{a}}\left(\alpha-\mathrm{NH}_{3}{ }^{+}\right)$ & Molecular structure \\
\hline Glycine & Gly & 75.07 & 9.60 & \\
\hline L-Alanine & Ala & 89.09 & 9.87 & \\
\hline L-Valine & Val & 117.15 & 9.62 & \\
\hline L-Proline & Pro & 115.13 & 10.60 & \\
\hline L-Histidine & His & 155.15 & 9.17 & \\
\hline L-Lysine & Lys & 146.19 & 8.95 & \\
\hline $\mathrm{L}-$ Arginine & Arg & 174.20 & 9.04 & \\
\hline
\end{tabular}


Table 2. Physical properties of AAPILs synthesized.

\begin{tabular}{cccc}
\hline AAPILs & Density & Color & Form \\
\hline P[VBIm][Gly] & 1.09962 & Yellowish & Solid \\
P[VBIm][Ala] & 1.02639 & Yellowish & Solid \\
P[VBIm][Val] & 0.99676 & Whitish & Solid \\
P[VBIm][Pro] & 1.12680 & Brownish & Solid \\
P[VBIm][His] & 1.15386 & Brownish & Solid \\
P[VBIm][Lys] & 1.10997 & Yellowish & Solid \\
P[VBIm][Arg] & 0.99946 & Yellowish & Solid \\
\hline
\end{tabular}


Table 3. $\mathrm{CO}_{2}$ absorption capacity $n_{C O 2} / n_{\text {monomer }}$ of AAPILs in the temperature range $288.15-308.15$ $\mathrm{K}$ and pressure up to 5 bar.

\begin{tabular}{|c|c|c|c|c|c|}
\hline \multicolumn{2}{|c|}{$T=288.15 \mathrm{~K}$} & \multicolumn{2}{|c|}{$T=298.15 \mathrm{~K}$} & \multicolumn{2}{|c|}{$T=308.15 \mathrm{~K}$} \\
\hline$P /$ bar & $\mathrm{mol}_{\mathrm{CO}_{2}} / \mathrm{mol}_{\text {monomer }}$ & $P /$ bar & $\mathrm{mol}_{\mathrm{CO}_{2}} / \mathrm{mol}_{\text {monomer }}$ & $P /$ bar & $\mathrm{mol}_{\mathrm{CO}_{2}} / \mathrm{mol}_{\text {monomer }}$ \\
\hline \multicolumn{6}{|c|}{$\mathrm{P}[\mathrm{VBIm}][\mathrm{Arg}]$} \\
\hline 0.2098 & 0.1663 & 0.2069 & 0.1515 & 0.2151 & 0.1056 \\
\hline 0.3787 & 0.2758 & 0.4661 & 0.2826 & 0.4251 & 0.1919 \\
\hline 0.5768 & 0.3678 & 0.6571 & 0.3547 & 0.7929 & 0.332 \\
\hline 0.8336 & 0.4675 & 0.9208 & 0.4304 & 1.0836 & 0.3953 \\
\hline 0.9488 & 0.4949 & 1.5000 & 0.5689 & 1.5000 & 0.5047 \\
\hline 1.5000 & 0.6279 & 2.0000 & 0.6576 & 2.0000 & 0.593 \\
\hline 2.0000 & 0.7062 & 2.5000 & 0.7297 & 2.5000 & 0.6621 \\
\hline 2.5000 & 0.8001 & 3.0000 & 0.7943 & 3.0000 & 0.7389 \\
\hline 3.0000 & 0.8470 & 3.5000 & 0.8460 & 3.5000 & 0.7964 \\
\hline 3.5000 & 0.9116 & 4.0000 & 0.9051 & 4.0000 & 0.8598 \\
\hline 4.0000 & 0.9683 & 4.5000 & 0.9550 & 4.5000 & 0.8982 \\
\hline 4.5000 & 1.0094 & 5.0000 & 1.0067 & 5.0000 & 0.9365 \\
\hline 5.0000 & 1.0583 & & & & \\
\hline \multicolumn{6}{|c|}{ P[VBIm][Lys] } \\
\hline 0.2449 & 0.2744 & 0.1825 & 0.1120 & 0.2069 & 0.1322 \\
\hline 0.4903 & 0.4209 & 0.3130 & 0.1864 & 0.3593 & 0.1913 \\
\hline 0.7070 & 0.4953 & 0.5350 & 0.2778 & 0.6014 & 0.2887 \\
\hline 0.9561 & 0.5725 & 0.8099 & 0.3797 & 1.0438 & 0.4278 \\
\hline 1.5000 & 0.6744 & 0.9966 & 0.4255 & 1.5000 & 0.5043 \\
\hline 2.0000 & 0.7411 & 1.5000 & 0.5345 & 2.0000 & 0.5669 \\
\hline 2.5000 & 0.7903 & 2.0000 & 0.6224 & 2.5000 & 0.6087 \\
\hline 3.0000 & 0.836 & 2.5000 & 0.6716 & 3.0000 & 0.6435 \\
\hline 3.5000 & 0.8781 & 3.0000 & 0.7278 & 3.5000 & 0.6956 \\
\hline 4.0000 & 0.9168 & 3.5000 & 0.7735 & 4.0000 & 0.7548 \\
\hline 4.5000 & 0.9378 & 4.0000 & 0.8157 & 4.5000 & 0.7791 \\
\hline 5.0000 & 0.9554 & 4.5000 & 0.8579 & 5.0000 & 0.8174 \\
\hline & & 5.0000 & 0.9107 & & \\
\hline \multicolumn{6}{|c|}{$\mathrm{P}[\mathrm{VBIm}][\mathrm{His}]$} \\
\hline 0.1337 & 0.1251 & 0.1120 & 0.0796 & 0.2069 & 0.1039 \\
\hline 0.2613 & 0.2057 & 0.3173 & 0.1867 & 0.3730 & 0.145 \\
\hline 0.5213 & 0.3113 & 0.6411 & 0.2937 & 0.6543 & 0.2106 \\
\hline 1.0032 & 0.4335 & 0.9794 & 0.3651 & 1.0247 & 0.2872 \\
\hline 1.5000 & 0.5114 & 1.5000 & 0.4365 & 1.5000 & 0.3392 \\
\hline 2.0000 & 0.5614 & 2.0000 & 0.4969 & 2.0000 & 0.3912 \\
\hline 2.5000 & 0.6058 & 2.5000 & 0.5353 & 2.5000 & 0.4377 \\
\hline 3.0000 & 0.6475 & 3.0000 & 0.571 & 3.0000 & 0.4732 \\
\hline 3.5000 & 0.6892 & 3.5000 & 0.6094 & 3.5000 & 0.5088 \\
\hline 4.0000 & 0.7253 & 4.0000 & 0.6369 & 4.0000 & 0.5361 \\
\hline 4.5000 & 0.7559 & 4.5000 & 0.6671 & 4.5000 & 0.5635 \\
\hline 5.0000 & 0.792 & 5.0000 & 0.6918 & 5.0000 & 0.5963 \\
\hline \multicolumn{6}{|c|}{$\mathrm{P}[\mathrm{VBIm}][$ Pro] } \\
\hline 0.1988 & 0.0870 & 0.2069 & 0.1072 & 0.1852 & 0.068 \\
\hline 0.3785 & 0.1553 & 0.3784 & 0.1571 & 0.3867 & 0.1225 \\
\hline 0.5876 & 0.2013 & 0.5874 & 0.1997 & 0.5738 & 0.1711 \\
\hline 0.7843 & 0.2535 & 0.7925 & 0.2411 & 0.7615 & 0.208 \\
\hline 0.9816 & 0.2833 & 0.9808 & 0.2655 & 0.9816 & 0.245 \\
\hline 1.5000 & 0.3653 & 1.5000 & 0.3361 & 1.5000 & 0.3033 \\
\hline 2.0000 & 0.4262 & 2.0000 & 0.3860 & 2.0000 & 0.348 \\
\hline 2.5000 & 0.4796 & 2.5000 & 0.4287 & 2.5000 & 0.3947 \\
\hline 3.0000 & 0.5243 & 3.0000 & 0.4615 & 3.0000 & 0.4316 \\
\hline
\end{tabular}




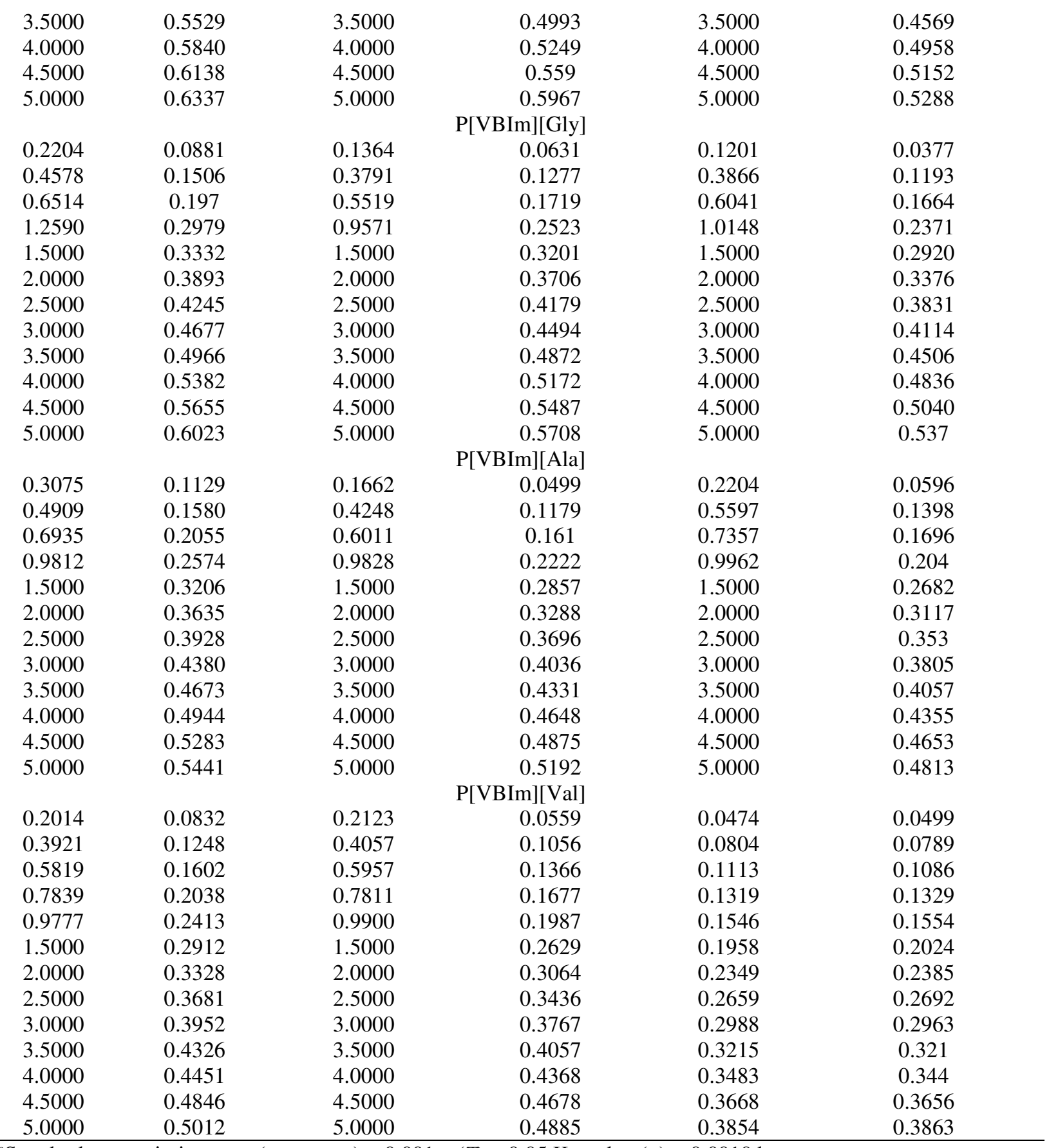

${ }^{a}$ Standard uncertainties are $\mathrm{u}_{\mathrm{r}}\left(n_{\mathrm{CO}_{2}} / n_{\mathrm{AALL}}\right)=0.001, \mathrm{u}(T)=0.05 \mathrm{~K}$, and $\mathrm{u}(p)=0.0010$ bar 
Table 4. Henry's law constant $(H)$, reaction equilibrium constant $\left(K_{x}\right)$, experiment constant $(C)$, the correlation coefficient $\left(R^{2}\right)$ and absolute average relative deviation (AARD) for $\mathrm{CO}_{2}$ absorption AAPILs at different temperatures $(T)$.

\begin{tabular}{|c|c|c|c|c|c|c|}
\hline AAPILs & $T / \mathrm{K}$ & $H$ (bar) & $K_{x}\left(b a r^{-1}\right)$ & $C$ & $R^{2}$ & ${ }^{\mathrm{a}} A A R D \%$ \\
\hline & 288.15 & $12.67 \pm 1.09$ & $0.89 \pm 0.72$ & 0.97 & 0.9995 & 1.28 \\
\hline \multirow{3}{*}{$\mathrm{P}[\mathrm{VBIm}][\mathrm{Arg}]$} & 298.15 & $15.07 \pm 1.02$ & $0.81 \pm 0.87$ & 0.90 & 0.9997 & 0.99 \\
\hline & 308.15 & $18.60 \pm 1.88$ & $0.77 \pm 0.90$ & 0.61 & 0.9992 & 1.46 \\
\hline & 288.15 & $15.51 \pm 0.78$ & $0.71 \pm 0.92$ & 0.99 & 0.9996 & 1.29 \\
\hline \multirow[t]{3}{*}{$\mathrm{P}[\mathrm{VBIm}][\mathrm{Lys}]$} & 298.15 & $17.12 \pm 1.59$ & $0.70 \pm 0.77$ & 0.97 & 0.9984 & 1.15 \\
\hline & 308.15 & $21.23 \pm 1.39$ & $0.67 \pm 1.05$ & 0.91 & 0.9985 & 1.15 \\
\hline & 288.15 & $18.04 \pm 0.92$ & $0.57 \pm 1.25$ & 0.94 & 0.9999 & 0.31 \\
\hline \multirow[t]{3}{*}{$\mathrm{P}[\mathrm{VBIm}][\mathrm{His}]$} & 298.15 & $21.82 \pm 1.26$ & $0.52 \pm 1.33$ & 0.61 & 0.9998 & 1.16 \\
\hline & 308.15 & $23.84 \pm 1.75$ & $0.45 \pm 1.61$ & 0.96 & 0.9990 & 1.23 \\
\hline & 288.15 & $22.76 \pm 2.03$ & $0.51 \pm 1.27$ & 0.95 & 0.9989 & 1.49 \\
\hline \multirow[t]{3}{*}{ P[VBIm][Pro] } & 298.15 & $24.27 \pm 1.66$ & $0.45 \pm 1.71$ & 0.99 & 0.9982 & 1.37 \\
\hline & 308.15 & $25.33 \pm 1.46$ & $0.41 \pm 1.53$ & 0.99 & 0.9989 & 1.51 \\
\hline & 288.15 & $22.87 \pm 2.24$ & $0.48 \pm 1.14$ & 0.75 & 0.9990 & 1.44 \\
\hline \multirow{3}{*}{ P[VBIm][Gly] } & 298.15 & $24.36 \pm 0.93$ & $0.44 \pm 1.68$ & 0.94 & 0.9996 & 1.42 \\
\hline & 308.15 & $25.57 \pm 1.03$ & $0.40 \pm 1.28$ & 0.99 & 0.9989 & 1.06 \\
\hline & 288.15 & $25.69 \pm 1.29$ & $0.43 \pm 1.51$ & 0.94 & 0.9996 & 1.31 \\
\hline \multirow[t]{3}{*}{$\mathrm{P}[\mathrm{VBIm}][\mathrm{Ala}]$} & 298.15 & $26.22 \pm 1.55$ & $0.39 \pm 1.31$ & 0.93 & 0.9999 & 1.18 \\
\hline & 308.15 & $28.06 \pm 1.35$ & $0.37 \pm 1.44$ & 0.91 & 0.9998 & 1.17 \\
\hline & 288.15 & $26.26 \pm 2.15$ & $0.38 \pm 1.80$ & 0.98 & 0.9996 & 1.35 \\
\hline \multirow[t]{2}{*}{$\mathrm{P}[\mathrm{VBIm}][\mathrm{Val}]$} & 298.15 & $27.27 \pm 1.45$ & $0.38 \pm 1.45$ & 0.79 & 0.9998 & 0.95 \\
\hline & 308.15 & $32.44 \pm 1.92$ & $0.29 \pm 1.86$ & 0.75 & 0.9993 & 1.44 \\
\hline
\end{tabular}


Table 5. The enthalpy of physical absorption $\left(\Delta H_{\text {sol }}\right)$ and the enthalpy of chemical absorption $\left(\Delta H_{e q}\right.$ ) of $\mathrm{CO}_{2}$ in AAPILs.

\begin{tabular}{ccc}
\hline AAPILs & $\Delta H_{\text {sol } / \mathrm{kJ} \cdot \mathrm{mol}^{-1}}$ & $\Delta H_{e q} / \mathrm{kJ} \cdot \mathrm{mol}^{-1}$ \\
\hline P[VBIm][Arg] & $-14.12 \pm 0.13$ & $-5.36 \pm 0.10$ \\
P[VBIm][Lys] & $-11.53 \pm 0.33$ & $-2.13 \pm 0.08$ \\
P[VBIm][His] & $-9.45 \pm 0.18$ & $-8.69 \pm 0.16$ \\
P[VBIm][Pro] & $-3.95 \pm 0.05$ & $-8.06 \pm 0.06$ \\
P[VBIm][Gly] & $-4.12 \pm 0.03$ & $-6.70 \pm 0.15$ \\
P[VBIm][Ala] & $-3.24 \pm 0.13$ & $-5.56 \pm 0.10$ \\
P[VBIm][Val] & $-7.77 \pm 0.27$ & $-9.86 \pm 0.72$ \\
\hline
\end{tabular}



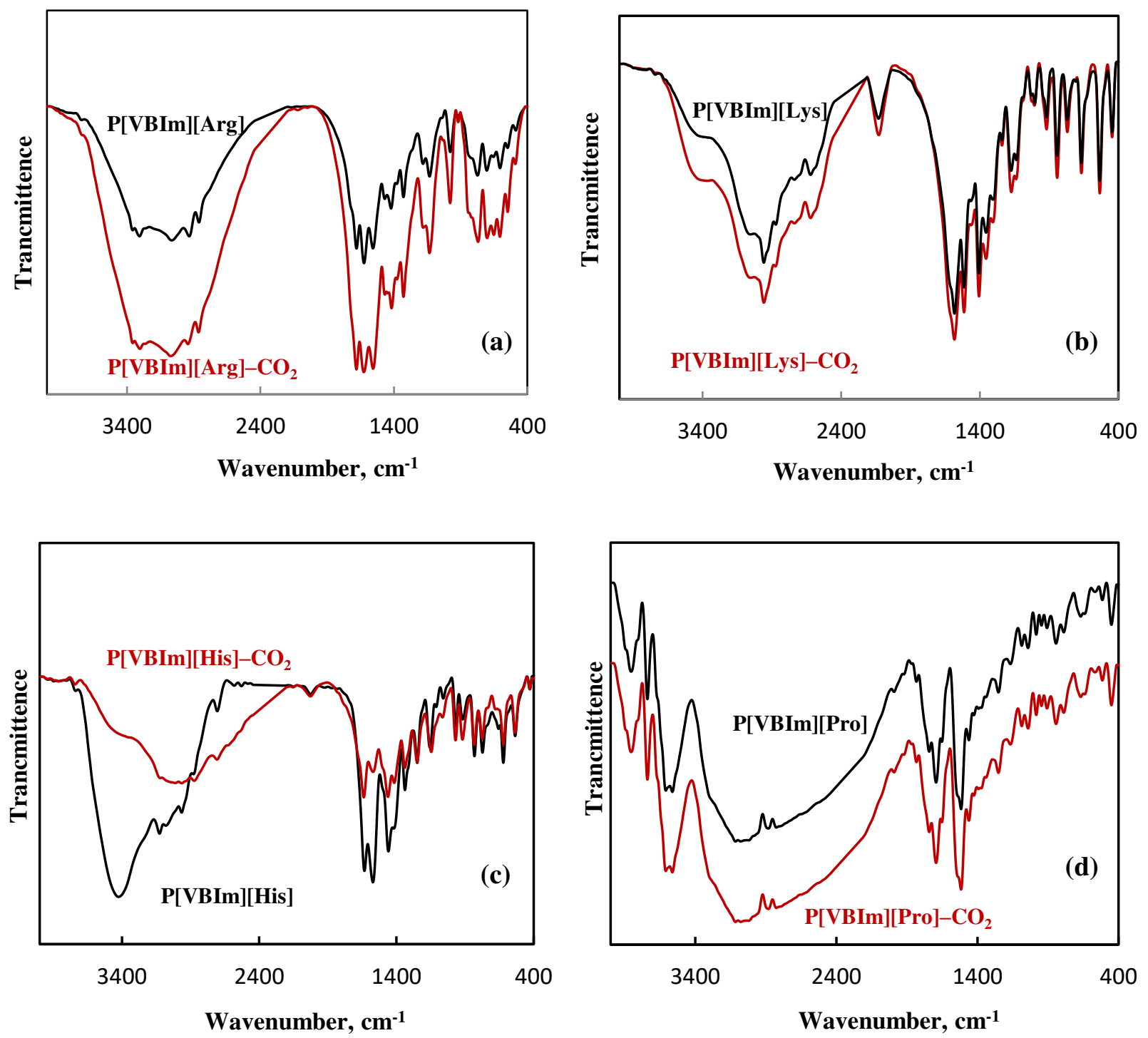

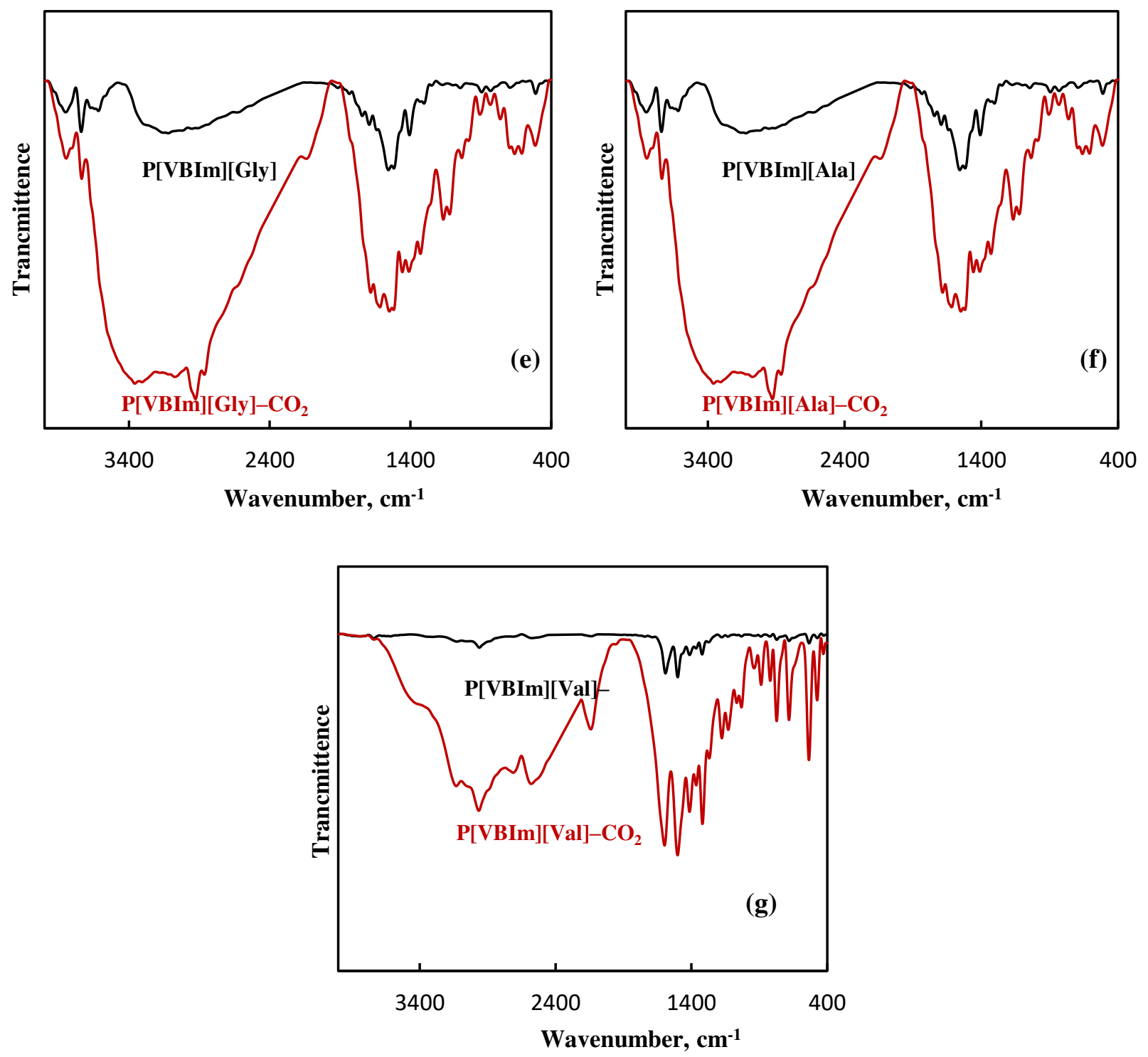

Fig. 1. FT-IR of AAPILs before and after $\mathrm{CO}_{2}$ absorption. 

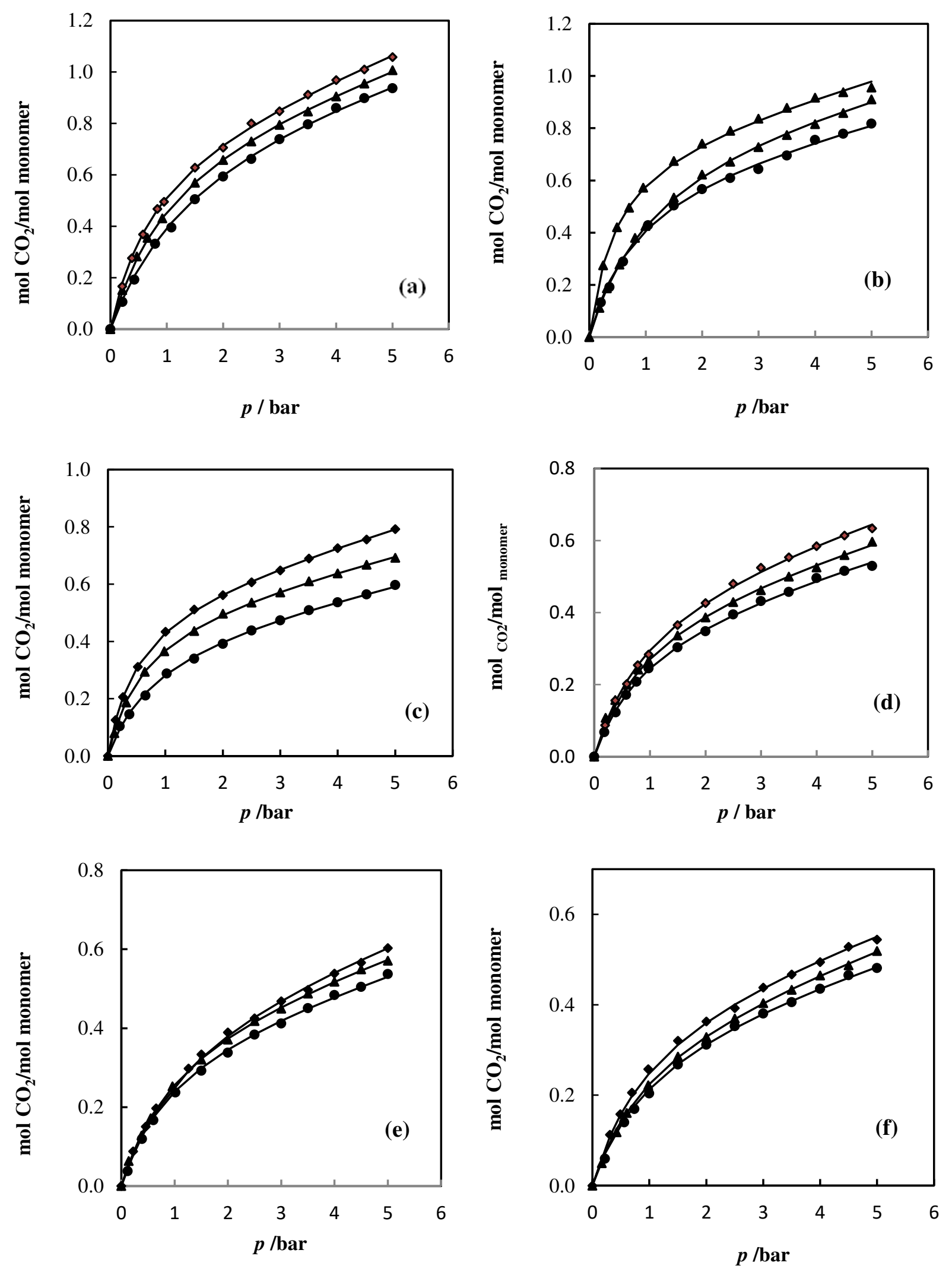


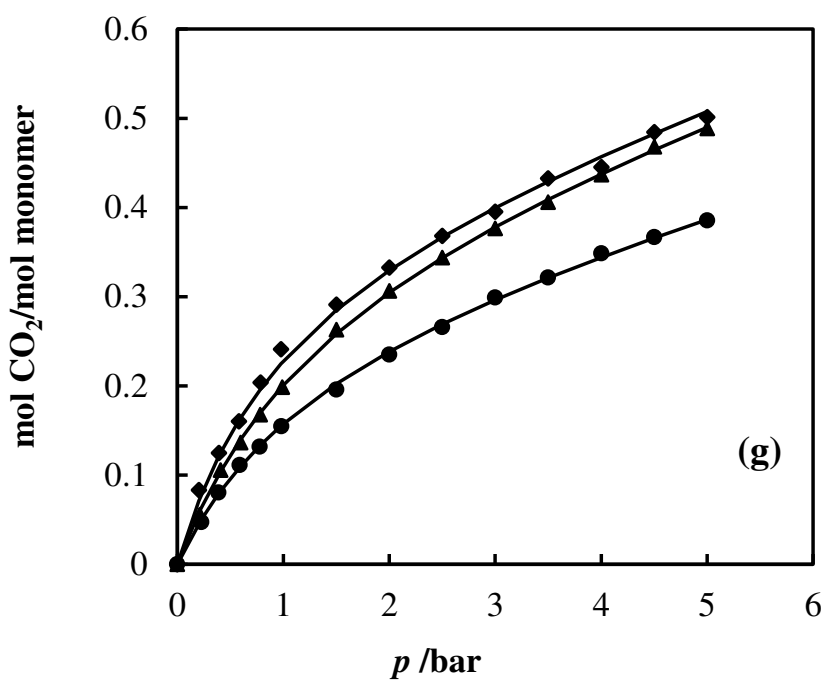

Fig. 2. The $\mathrm{CO}_{2}$ absorption in (a) P[VBIm][Arg]; (b) P[VBIm][Lys]; (c) P[VBIm][His]; (d) P[VBIm][Pro]; (e) P[VBIm][Gly]; (f) P[VBIm][Ala]; (g) P[VBIm][Val] at different

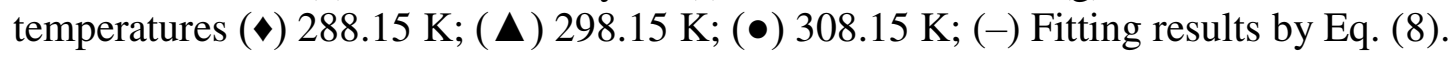




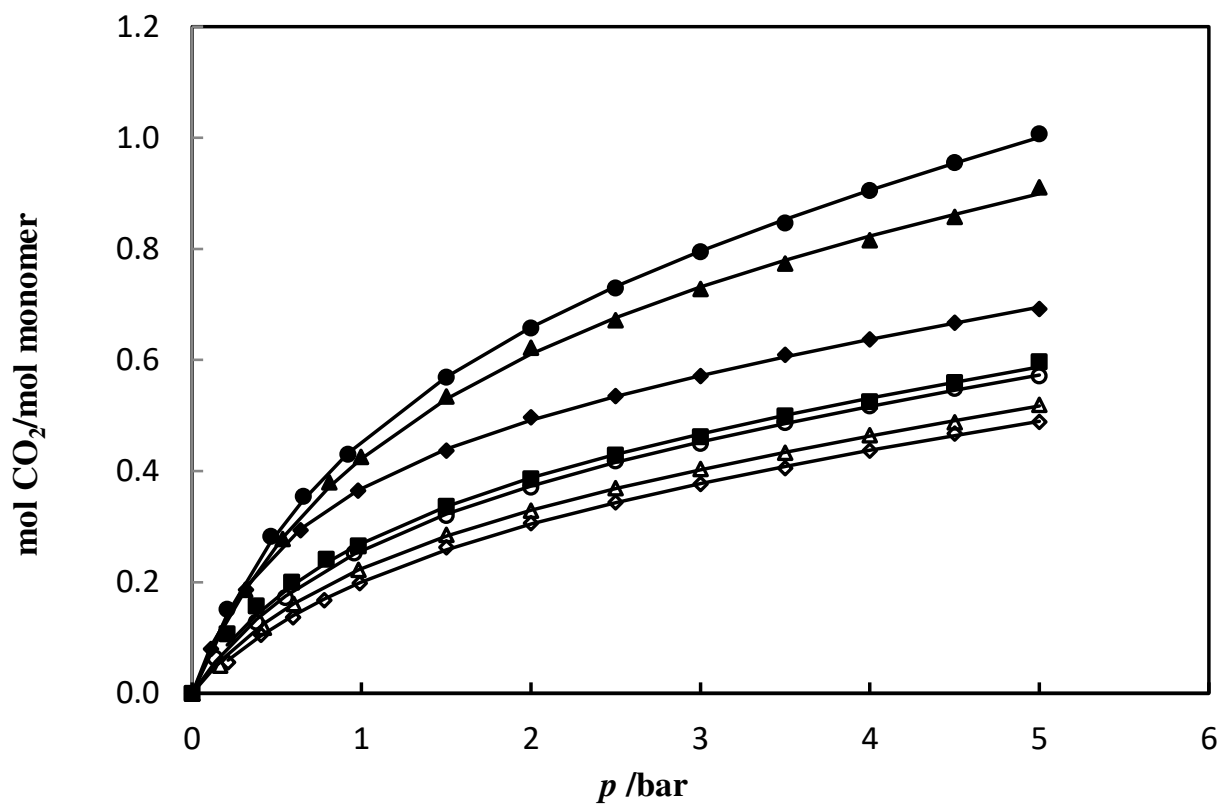

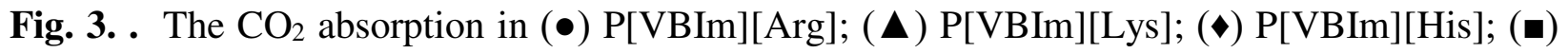

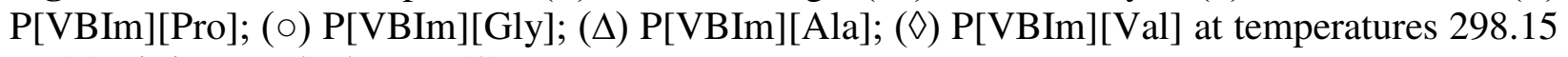
K; (-) Fitting results by Eq. (8). 


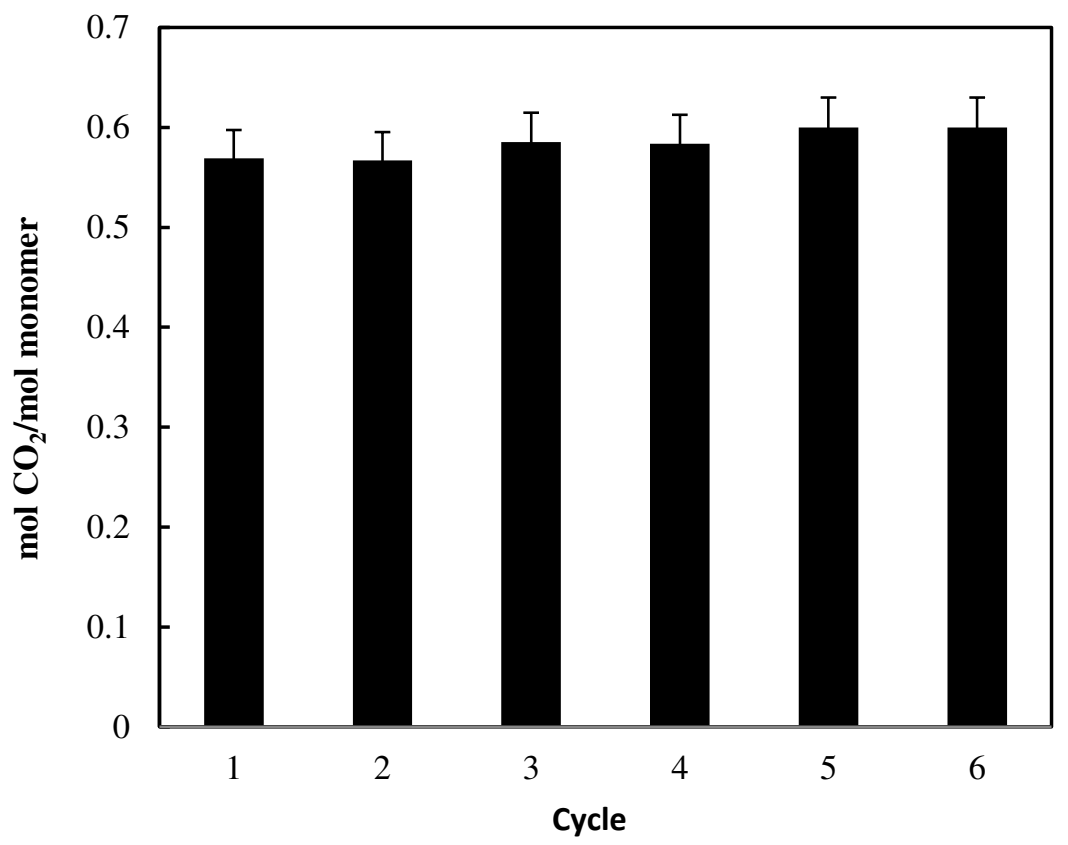

Fig. 4. The $\mathrm{CO}_{2}$ absorption capacity of $\mathrm{P}[\mathrm{VBIm}][\mathrm{Arg}]$ at $p=1$ bar and $T=298.15 \mathrm{~K}$ in six absorption/desorption cycles. 